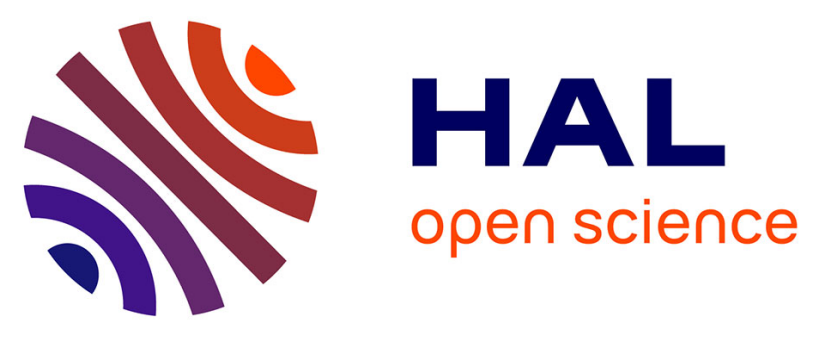

\title{
Two-Photon-Triggered Drug Delivery in Cancer Cells Using Nanoimpellers
}

Jonas Croissant, Marie Maynadier, Audrey Gallud, Harmel Peindy n'Dongo, Jeff Nyalosaso, Gaëlle Derrien, Clarence Charnay, Jean-Olivier Durand, Laurence Raehm, Françoise Serein-Spirau, et al.

\section{To cite this version:}

Jonas Croissant, Marie Maynadier, Audrey Gallud, Harmel Peindy n'Dongo, Jeff Nyalosaso, et al.. Two-Photon-Triggered Drug Delivery in Cancer Cells Using Nanoimpellers. Angewandte Chemie International Edition, 2013, 52 (51), pp.13813-13817. 10.1002/anie.201308647 . hal-02875559

\section{HAL Id: hal-02875559 https://hal.science/hal-02875559}

Submitted on 8 Jan 2021

HAL is a multi-disciplinary open access archive for the deposit and dissemination of scientific research documents, whether they are published or not. The documents may come from teaching and research institutions in France or abroad, or from public or private research centers.
L'archive ouverte pluridisciplinaire HAL, est destinée au dépôt et à la diffusion de documents scientifiques de niveau recherche, publiés ou non, émanant des établissements d'enseignement et de recherche français ou étrangers, des laboratoires publics ou privés. 
Published in final edited form as:

Angew Chem Int Ed Engl. 2013 December 16; 52(51): 13813-13817. doi:10.1002/anie.201308647.

\title{
Two-Photon-Triggered Drug Delivery in Cancer Cells Using Nanoimpellers ${ }^{\star *}$
}

\author{
Jonas Croissant \\ Institut Charles Gerhardt Montpellier UMR-5253 CNRS-UM2-ENSCM-UM1, cc 1701 Place \\ Eugène Bataillon, 34095 Montpellier Cedex 05 (France)
}

\section{Dr. Marie Maynadier}

Institut des Biomolécules Max Mousseron UMR 5247 CNRS Faculté de Pharmacie, 15 Avenue Charles Flahault 34093 Montpellier Cedex 05 (France)

\section{Audrey Gallud}

Institut des Biomolécules Max Mousseron UMR 5247 CNRS Faculté de Pharmacie, 15 Avenue Charles Flahault 34093 Montpellier Cedex 05 (France)

\section{Dr. Harmel Peindy N'Dongo}

Institut Charles Gerhardt Montpellier UMR-5253 CNRS-UM2-ENSCM-UM1, cc 1701 Place Eugène Bataillon, 34095 Montpellier Cedex 05 (France)

\section{Dr. Jeff L. Nyalosaso}

Institut Charles Gerhardt Montpellier UMR-5253 CNRS-UM2-ENSCM-UM1, cc 1701 Place Eugène Bataillon, 34095 Montpellier Cedex 05 (France)

\section{Dr. Gaëlle Derrien}

Institut Charles Gerhardt Montpellier UMR-5253 CNRS-UM2-ENSCM-UM1, cc 1701 Place Eugène Bataillon, 34095 Montpellier Cedex 05 (France)

\section{Dr. Clarence Charnay}

Institut Charles Gerhardt Montpellier UMR-5253 CNRS-UM2-ENSCM-UM1, cc 1701 Place Eugène Bataillon, 34095 Montpellier Cedex 05 (France)

\section{Dr. Jean-Olivier Durand ${ }^{\star}$}

Institut Charles Gerhardt Montpellier UMR-5253 CNRS-UM2-ENSCM-UM1, cc 1701 Place Eugène Bataillon, 34095 Montpellier Cedex 05 (France)

\section{Dr. Laurence Raehm}

Institut Charles Gerhardt Montpellier UMR-5253 CNRS-UM2-ENSCM-UM1, cc 1701 Place Eugène Bataillon, 34095 Montpellier Cedex 05 (France)

\section{Prof. Françoise Serein-Spirau}

Institut Charles Gerhardt Montpellier UMR-5253 CNRS-UM2-ENSCM-UM1, cc 1701 Place Eugène Bataillon, 34095 Montpellier Cedex 05 (France)

\section{Dr. Nathalie Cheminet}

\footnotetext{
${ }^{[* *}$ Support from ANR P2N Mechanano, PUF program 20091853, and NIH (grant number CA133697) is gratefully acknowledged. We thank S. De Rossi and V. Georget from the Montpellier RIO imaging platform for assistance in the two-photon microscopy experiments.

(C) 2013 Wiley-VCH Verlag GmbH \& Co. KGaA, Weinheim

durand@um2.frmagali.gary-bobo@univ-montp1.frzink@chem.ucla.edu.

Supporting information for this article is available on the WWW under http://dx.doi.org/10.1002/anie.201308647.
} 
Institut Charles Gerhardt Montpellier UMR-5253 CNRS-UM2-ENSCM-UM1, cc 1701 Place Eugène Bataillon, 34095 Montpellier Cedex 05 (France)

Dr. Thibaut Jarrosson

Institut Charles Gerhardt Montpellier UMR-5253 CNRS-UM2-ENSCM-UM1, cc 1701 Place Eugène Bataillon, 34095 Montpellier Cedex 05 (France)

\section{Dr. Olivier Mongin}

Institut Des Sciences Chimiques de Rennes CNRS UMR 6226, Université Rennes 1 Campus Beaulieu, 35042 Rennes Cedex (France)

\section{Dr. Mireille Blanchard-Desce}

Université Bordeaux 1 Institut des Sciences Moléculaires, UMR CNRS 5255351 Cours de la Libération, 33405 Talence Cedex (France)

\section{Dr. Magali Gary-Bobo*}

Institut des Biomolécules Max Mousseron UMR 5247 CNRS Faculté de Pharmacie, 15 Avenue Charles Flahault 34093 Montpellier Cedex 05 (France)

\section{Dr. Marcel Garcia}

Institut des Biomolécules Max Mousseron UMR 5247 CNRS Faculté de Pharmacie, 15 Avenue Charles Flahault 34093 Montpellier Cedex 05 (France)

\section{Dr. Jie Lu}

Department of Microbiology, Immunology and Molecular Genetics University of California Los Angeles 405 Hilgard Avenue, Los Angeles, CA 90095 (USA)

\section{Prof. Fuyuhiko Tamanoi}

Department of Microbiology, Immunology and Molecular Genetics University of California Los Angeles 405 Hilgard Avenue, Los Angeles, CA 90095 (USA)

\section{Dr. Derrick Tarn}

Department of Chemistry and Biochemistry University of California Los Angeles 405 Hilgard Avenue, Los Angeles, CA 90095 (USA)

\section{Tania M. Guardado-Alvarez}

Department of Chemistry and Biochemistry University of California Los Angeles 405 Hilgard Avenue, Los Angeles, CA 90095 (USA)

Prof. Jeffrey I. Zink ${ }^{*}$

Department of Chemistry and Biochemistry University of California Los Angeles 405 Hilgard Avenue, Los Angeles, CA 90095 (USA)

\section{Abstract}




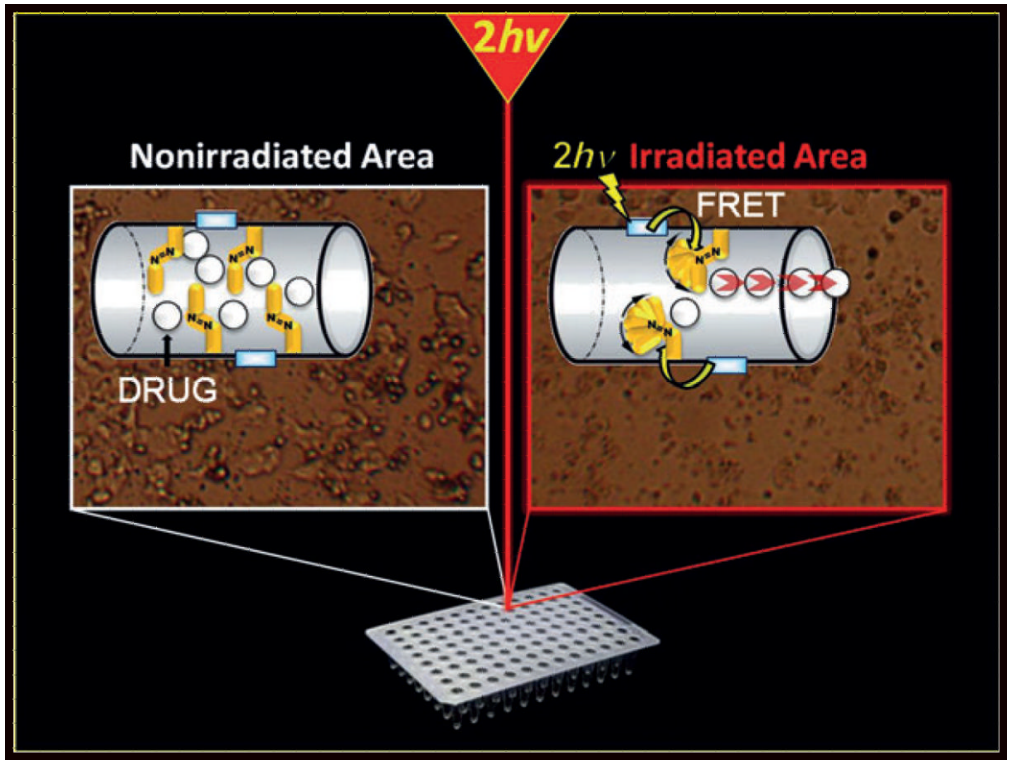

A therapy of cancer cells: Two-photon-triggered camptothecin delivery (see picture) with nanoimpellers was studied in MCF-7 breast cancer cells. A fluorophore with a high two-photon absorption cross-section was first incorporated in the nanoimpellers. Fluorescence resonance energy transfer (FRET) from the fluorophore to the azobenzene moiety was demonstrated.

\section{Keywords}

azobenzene; cancer; drug delivery; mesoporous materials; two-photon excitation

Nowadays, remote activation of nanoparticles (NPs) by light for biomedical applications has become an important area of research. ${ }^{[1]}$ Among the different nano-objects, mesoporous silica nanoparticles (MSN) for light-triggered drug delivery applications have recently emerged and the field is expanding. Since the pioneering works of Zink, ${ }^{[2,3]} \mathrm{Kim},{ }^{[4]} \mathrm{Lin},{ }^{[5]}$ and coworkers, many different systems have been described so far involving photocleavage, ${ }^{[4-11]}$ photodissociation, ${ }^{[12]}$ photoisomerization, ${ }^{[13-21]}$ photorelease, ${ }^{[22]}$ photothermal ${ }^{[23,24]}$ photo-plasmonic heating, ${ }^{[25-28]}$ and up-conversion photoisomerization. ${ }^{[29]}$ Except for up-conversion, plasmonic and photothermal heating systems which can be activated with near-infrared (NIR) light, the majority of the studies is a proof-of-concept and was performed with UV/Vis light. Therefore the applications are limited because UV/Vis light can damage cells ${ }^{[30]}$ and does not penetrate deep inside tissues. Using two-photon excitation (TPE) in the NIR region instead of UV/Vis light has many advantages such as deeper penetration in tissues (down to $2 \mathrm{~cm}$ ), lower scattering losses, and three-dimensional spatial resolution. TPE is therefore highly suitable for applications in nanomedicine. Indeed nanomedicine aims at suppressing the side-effects of chemotherapeutic drugs, but the challenge to deliver on-demand such drugs with spatial and temporal accuracy remains unsolved. A two-photon actuated nanovehicle would provide an excellent spatial and temporal control of the release in tumors, which is not achieved with classical NIR systems. Only one example of photocleavage with MSN was described using TPE. ${ }^{[10]}$ The drug was covalently attached to the MSN through the photocleavable linker, which necessitated the functionalization of the drug. Moreover, the MSN were tested on cancer cells with UV/Vis light. 
Here, we report the synthesis of nanoimpellers ${ }^{[20]}$ functionalized with a two-photon fluorophore F with a high two-photon absorption cross-section, suitable for Förster resonance energy transfer (FRET) to photoizomerize azobenzene A moieties in the NIR region (see Scheme 1). The nanoimpeller groups pending in the porous framework allow the physical entrapment of the anticancer drug camptothecin, which is then kicked out of the pores by two-photon-triggered photoisomerization, and finally leads to in vitro cancer cell killing.

First, a novel fluorophore for TPE possessing two triethoxysilane moieties was designed and fully characterized (see the Supporting Information). The maximum fluorescence emission $\left(\lambda_{\mathrm{ex}}=385 \mathrm{~nm}\right)$ of the fluorophore was $420 \mathrm{~nm}$ in tetrahydrofuran (THF), with a quantum yield of $88 \%$.

The fluorophore or/and mono-triethoxysilylated azobenzene were co-condensed with tetraethoxysilane (TEOS) in basic media with cetyltrimethylammonium bromide (CTAB) following our synthesis procedure of MSN. ${ }^{[31]}$ The as-prepared nanomaterials were labeled $\mathrm{MA}$ and MF, respectively for the mesoporous silica-azobenzene and mesoporous silicafluorophore modification, whereas the co-condensation of both the azobenzene and the fluorophore with different proportions led to MAF-x (see Table 1).

The characterizations of the nanoimpellers after surfactant removal confirmed the nanosized mesoporous organosilicas (see Scheme $1 \mathrm{~d}$ and Figures S1-S7 in the Supporting Information) with high specific surface areas suitable for cargo transportation.

FRET between the fluorophore and azobenzene moieties with MAF nanoimpellers was then studied by steady-state fluorescence experiments. First the fluorescence-emission quantum yield ( $\Phi_{\mathrm{F}}$ ) of the fluorophore inside the MSN (MF sample) was determined to be $58 \%$. The fluorescence emission of the MAF materials was quenched when the azobenzene groups were co-condensed with the fluorophore showing the FRET mechanism from the fluorophore to the azobenzene with MAF nanoimpellers (see Figure 1). When the A/F ratio increased the fluorescence quantum yield $\Phi_{\mathrm{F}}$ decreased accordingly. The energy-transfer quantum yield ( $\left.\Phi_{\mathrm{ET}}\right)$ increased and was maximum for MAF-4 (Table 2). The same trend was observed in the work of Lo and co-workers ${ }^{[32]}$ were fluorescein isothiocyanate was able to transfer its energy with a high quantum yield to a porphyrin photosensitizer, in MSN, for photodynamic TPE therapy. The two-photon absorption cross-sections $\sigma_{2}$ of the fluorophore and of MF and MAF samples were determined (Figure 2) and reached a maximum at 700 $\mathrm{nm}$. The two-photon absorption properties of the fluorophore were retained in the materials and no decrease of $\sigma_{2}$ was noticed after encapsulation.

The nanoimpellers MA and MAF were then loaded with rhodamine B (2 to 5\% in mass), to give $\mathrm{MA}+\mathrm{R}$ and $\mathrm{MAF}+\mathrm{R}$, respectively, in water to study cargo release under one-photon excitation. After centrifugation and extensive washing, the nanoparticles were put at the bottom of a quartz cell and the cell was carefully filled with water. The release of the cargo was monitored by UV/Vis spectroscopy (see Figure 3 and Figure S8 in the Supporting Information). No release was noticed without irradiation. UV irradiation at $365 \mathrm{~nm}$ triggered the release of the cargo showing the efficiency of all the nanoimpellers in water.

The nanoimpellers were configured for two-photon activation, therefore an in vitro study was led on MCF-7 breast cancer cell line, and the laser excitation was performed with a Carl Zeiss two-photon confocal microscope. The cellular uptake was assessed by two-photon fluorescence imaging. The cell walls were stained with a cell mask 15 minutes before the imaging experiments. The remaining fluorescence of the fluorophore ( $\Phi_{\mathrm{F}}: 2.5$ to $0.5 \%$, see Table 2) was taken into advantage to localize the MAF nanoimpellers. The slight emission 
of MAF-3 and MAF-4 was localized within the cells thus demonstrating the successful internalization of the nanoimpellers (see Figure 4 and Figure S9).

The nanoimpellers loaded with camptothecin $(\mathrm{MA}+\mathrm{C}, \mathrm{MAF}+\mathrm{C})$ were then screened under TPE in MCF-7 cancer cells. Cells were incubated with nanoimpellers in a 384 multiwell plate. Irradiation was performed with a Carl Zeiss microscope at very short time, with a focused laser beam and at maximum laser power (laser power input $3 \mathrm{~W}$, laser power output before the objective $900 \mathrm{~mW} \mathrm{~cm}{ }^{-2}$ ). The well was irradiated with three scans of $1.57 \mathrm{~s} \mathrm{each}$ per irradiated area, in four different areas, without overlaps between irradiated areas, with an objective: Carl Zeiss numerical aperture 0.3, 10-fold magnification. Half of the well was irradiated with this technique. The MTT assay was performed two days after irradiation. MA, MF, and MAF-4 nanoparticles did not induce cell death, with or without irradiation in the absence of camptothecin (see Figure S11). We further verify the safety of these nanoparticles by a incubation time of 4 days with increasing dose of MAF-4 on normal fibroblasts and MCF-7 cancer cells (Figure S10). Nanoimpellers were thus not toxic for cells and direct cancer cell killing (photothermal effect or ROS generation) was not observed. When loaded with camptothecin, MAF-1+C and MAF-2+C did not induce more killing of cancer cells under TPE than without irradiation which is probably correlated to the low A/F ratio (Figure 5a). By contrast, when the $\mathrm{A} / \mathrm{F}$ ratio increased, more cancer cell death was observed with MAF-3+C and MAF-4+C nanoimpellers under TPE than without irradiation, and the best result was obtained with MAF-4+C nanoimpeller possessing an A/F ratio of 17 and a high energy-transfer quantum yield (see ESI S9).

Hence, further in vitro experiments were led at different concentrations (from 20 to 80 $\mu \mathrm{gmL}^{-1}$ ) with $\mathrm{MA}+\mathrm{C}$ and MAF-4+C nanoimpellers (Figure $5 \mathrm{~b}$ ). MA+C nanoimpeller which does not possess the two-photon fluorophore did not kill cancer cells under TPE (see Figure $5 b)$ at $20 \mu \mathrm{gmL}^{-1}$ and no difference was observed between irradiated and nonirradiated cells with $\mathrm{MA}+\mathrm{C}$ nanoimpeller at higher concentration. By contrast MAF- $4+\mathrm{C}$ nanoimpeller was efficient in killing cancer cells at 20 and $40 \mu \mathrm{gmL}^{-1}$, under TPE and up to $40 \%$ of cancer cell death was observed. At $80 \mu \mathrm{gmL}^{-1}$ MAF- $4+\mathrm{C}$ nanoimpeller induced $30 \%$ of cancer cell death without irradiation and $75 \%$ cell death with irradiation. These results demonstrate that the fluorophore was necessary to observe cancer cell death with nanoimpellers under TPE at short time of irradiation, focused laser beam and high power. Note that $\mathrm{MA}+\mathrm{C}$ and MAF-4+C were both efficient in inducing cancer cell killing under different conditions for TPE (Figures S12-S13). Furthermore, premature release of camptothecin was not observed in aqueous solution without irradiation (Figure S14).

In conclusion, we have designed nanoimpellers with a two-photon fluorophore possessing a high two-photon absorption cross-section, leading to nanoimpellers configured for TPE with FRET from the fluorophore to the azobenzene. The residual fluorescence of the nanoimpellers allowed to perform TPE fluorescence imaging in cancer cells demonstrating the internalization of the nanoimpellers. Nanoimpeller MAF-4+C with a high energy transfer quantum yield from the fluorophore to the azobenzene moiety was able to induce cancer cell death under these TPE conditions and was not toxic to cells without irradiation at low concentration. Work is in progress to further extend the scope and applications of this methodology.

\section{Experimental Section}

Two-photon Induced drug delivery: Human breast cancer cells MCF-7 (purchased from ATCC) were cultured in Dulbecco's Modified Eagle's Medium (DMEM) supplemented with $10 \%$ fetal bovine serum and $50 \mu \mathrm{gmL}^{-1}$ gentamycin. All cells were allowed to grow in humidified atmosphere at $37^{\circ} \mathrm{C}$ under $5 \% \mathrm{CO}_{2}$. For in vitro phototoxicity, MCF-7 cells were 
seeded into a 384 multiwell glass-bottomed plate (thickness $0.17 \mathrm{~mm}$ ), with a black polystyrene frame, 2000 cells per well in $50 \mu \mathrm{L}$ of culture medium, and allowed to grow for $24 \mathrm{~h}$. Nanoimpellers loaded with camptothecin were then dispersed under ultrasound in phosphate-buffered saline (PBS) at a concentration of $1 \mathrm{mgmL}^{-1}$ and cells were then incubated for $20 \mathrm{~h}$ with or without nanoimpellers at a final concentration of 20 to 80 $\mu \mathrm{gmL}^{-1}$ in DMEM. After incubation with nanoimpellers, the cells were washed twice, maintained in fresh culture medium, and then submitted (or not) to laser irradiation using the Carl Zeiss Microscope (laser power input $3 \mathrm{~W}$ ). Half of the well was irradiated at $760 \mathrm{~nm}$ by three scans of $1.57 \mathrm{~s}$ duration in four different areas of the well. The laser beam was focused by a microscope objective lens (Carl Zeiss 10-fold magnification/objective 0.3 EC PlanNeofluar). The scan size does not allow irradiating more areas without overlapping. After 2 days, the MTS (3-(4,5-dimethylthiazol-2-yl)-5-(3-carboxymethoxyphenyl)-2-(4sulfonyl)-2H-tetrazolium) colorimetric bioassay was performed (as previously described) and was corrected according to the following formula $\mathrm{Abs}_{\text {control }^{-2}}$

$\left(\mathrm{Abs}_{\text {control }}-\mathrm{Abs}_{\text {Nanoimpellers }}\right)$ where $\mathrm{Abs}$ is absorption.

\section{Supplementary Material}

Refer to Web version on PubMed Central for supplementary material.

\section{References}

1. Tong R, Kohane DS. Wiley Interdiscip. Rev. Nanomed. Nanobiotechnol. 2012; 4:638-662. [PubMed: 22887840]

2. Johansson E, Choi E, Angelos S, Liong M, Zink JI. J. Sol-Gel Sci. Technol. 2008; 46:313-322.

3. Nguyen TD, Leung KCF, Liong M, Liu Y, Stoddart F, Zink JI. Adv. Funct. Mater. 2007; 17:21012110.

4. Park C, Lee K, Kim C. Angew. Chem. 2009; 121:1301-1304.Angew. Chem. Int. Ed. 2009; 48:1275-1278.

5. Vivero-Escoto JL, Slowing II, Wu CW, Lin VSY. J. Am. Chem. Soc. 2009; 131:3462-3463. [PubMed: 19275256]

6. Kneževic NŽ, Lin VSY. Nanoscale. 2013; 5:1544-1551. [PubMed: 23322330]

7. He D, He X, Wang K, Cao J, Zhao Y. Langmuir. 2012; 28:4003-4008. [PubMed: 22309360]

8. Agostini A, Sancenon F, Martinez-Manez R, Marcos MD, Soto J, Amoros P. Chem. Eur. J. 2012; 18:12218-12221. [PubMed: 22907729]

9. Kneževic NŽ, Trewyn BG, Lin VSY. Chem. Eur. J. 2011; 17:3338-3342. [PubMed: 21337435]

10. Lin QN, Huang Q, Li CY, Bao CY, Liu ZZ, Li FY, Zhu LY. J. Am. Chem. Soc. 2010; 132:1064510647. [PubMed: 20681684]

11. Lai J, Mu X, Xu Y, Wu X, Wu C, Li C, Chen J, Zhao Y. Chem. Commun. 2010; 46:7370-7372.

12. He D, He X, Wang K, Cao J, Zhao Y. Adv. Funct. Mater. 2012; 22:4704-4710.

13. Wang Y, Li B, Zhang L, Song H, Zhang L. Acs Appl. Mater. Interfaces. 2013; 5:11-15. [PubMed: 23245393]

14. Yuan Q, Zhang Y, Chen T, Lu D, Zhao Z, Zhang X, Li Z, Yan C-H, Tan W. Acs Nano. 2012; 6:6337-6344. [PubMed: 22670595]

15. Yan H, Teh C, Sreejith S, Zhu L, Kwok A, Fang W, Ma X, Kim Truc N, Korzh V, Zhao Y. Angew. Chem. 2012; 124:8498-8502.Angew. Chem. Int. Ed. 2012; 51:8373-8377.

16. Wen Y, Xu L, Wang W, Wang D, Du H, Zhang X. Nanoscale. 2012; 4:4473-4476. [PubMed: 22751906]

17. Mei X, Yang S, Chen D, Li N, Li H, Xu Q, Ge J, Lu J. Chem. Commun. 2012; 48:10010-10012.

18. Lau YA, Henderson BL, Lu J, Ferris DP, Tamanoi F, Zink JI. Nanoscale. 2012; 4:3482-3489. [PubMed: 22552632] 
19. Ferris DP, Zhao YL, Khashab NM, Khatib HA, Stoddart JF, Zink JI. J. Am. Chem. Soc. 2009; 131:1686-1688. [PubMed: 19159224]

20. Lu J, Choi E, Tamanoi F, Zink JI. Small. 2008; 4:421-426. [PubMed: 18383576]

21. Angelos S, Choi E, Voegtle F, De Cola L, Zink JI. J. Phys. Chem. C. 2007; 111:6589-6592.

22. Kneževic NŽ, Trewyn BG, Lin VSY. Chem. Commun. 2011; 47:2817-2819.

23. Singh AK, Hahn MA, Gutwein LG, Rule MC, Knapik JA, Moudgil BM, Grobmyer SR, Brown SC. Int. J. Nanomed. 2012; 7:2739-2750.

24. Gutwein LG, Singh AK, Hahn MA, Rule MC, Knapik JA, Moudgil BM, Brown SC, Grobmyer SR. Int. J. Nanomed. 2012; 7:351-357.

25. Jiang Z, Dong B, Chen B, Wang J, Xu L, Zhang S, Song H. Small. 2013; 9:604-612. [PubMed: 23112140]

26. Zhang Z, Wang L, Wang J, Jiang X, Li X, Hu Z, Ji Y, Wu X, Chen C. Adv. Mater. 2012; 24:14181423. [PubMed: 22318874]

27. Yang X, Liu X, Liu Z, Pu F, Ren J, Qu X. Adv. Mater. 2012; 24:2890-2895. [PubMed: 22539076]

28. Croissant J, Zink JI. J. Am. Chem. Soc. 2012; 134:7628-7631. [PubMed: 22540671]

29. Liu J, Bu W, Pan L, Shi J. Angew. Chem. 2013; 125:4471-4475.Angew. Chem. Int. Ed. 2013; 52:4375-4379.

30. Kushibiki T, Hirasawa T, Okawa S, Ishihara M. Photomed. Laser Surgery. 2013; 31:95-104.

31. Gary-Bobo M, Mir Y, Rouxel C, Brevet D, Basile I, Maynadier M, Vaillant O, Mongin O, Blanchard-Desce M, Morere A, Garcia M, Durand J-O, Raehm L. Angew. Chem. 2011; 123:11627-11631.Angew. Chem. Int. Ed. 2011; 50:11425-11429.

32. Cheng S-H, Hsieh C-C, Chen N-T, Chu C-H, Huang C-M, Chou P-T, Tseng F-G, Yang C-S, Mou C-Y, Lo L-W. Nano Today. 2011; 6:552-563. 
a

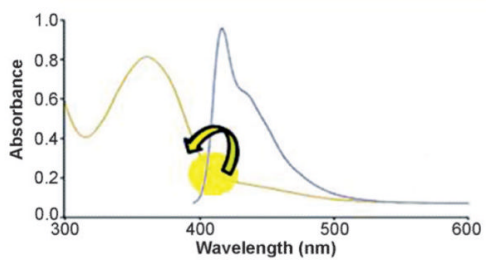

b
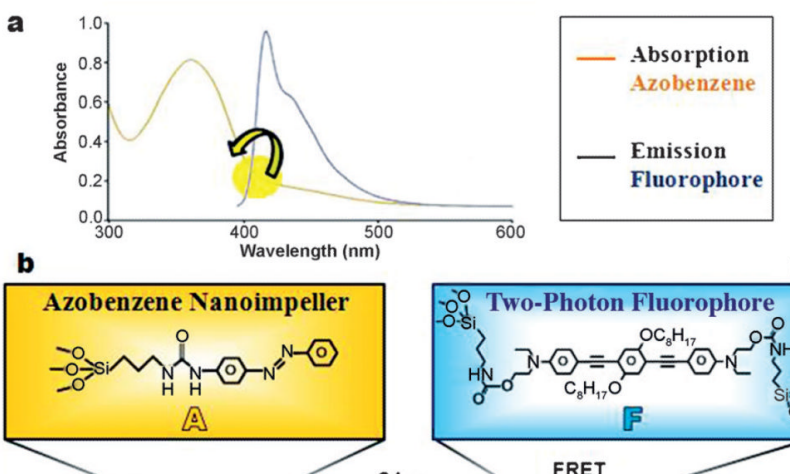

Fluorophore

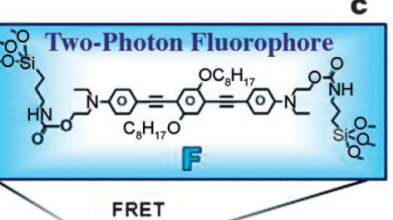

RET

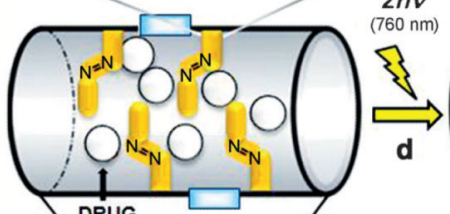

$(760 \mathrm{~nm})$

DRUG
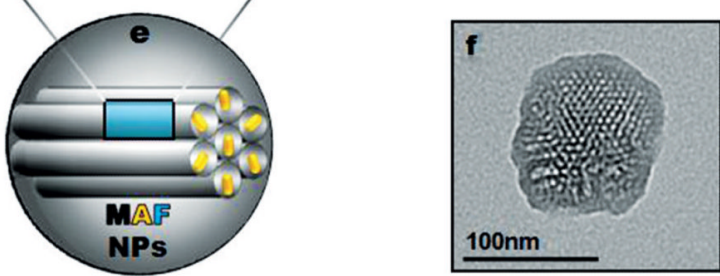

Scheme 1.

Mesoporous silica nanoparticles combining b) azobenzene moieties A and c) a two-photon fluorophore F. The design of the so-called MAF nanoimpellers allows a two-photon (760 $\mathrm{nm}$ ) activated release of drug molecules by a) FRET and d) photoisomerisation of azobenzene. e) Nanoimpellers and f) their transmission electron microscopy image. 

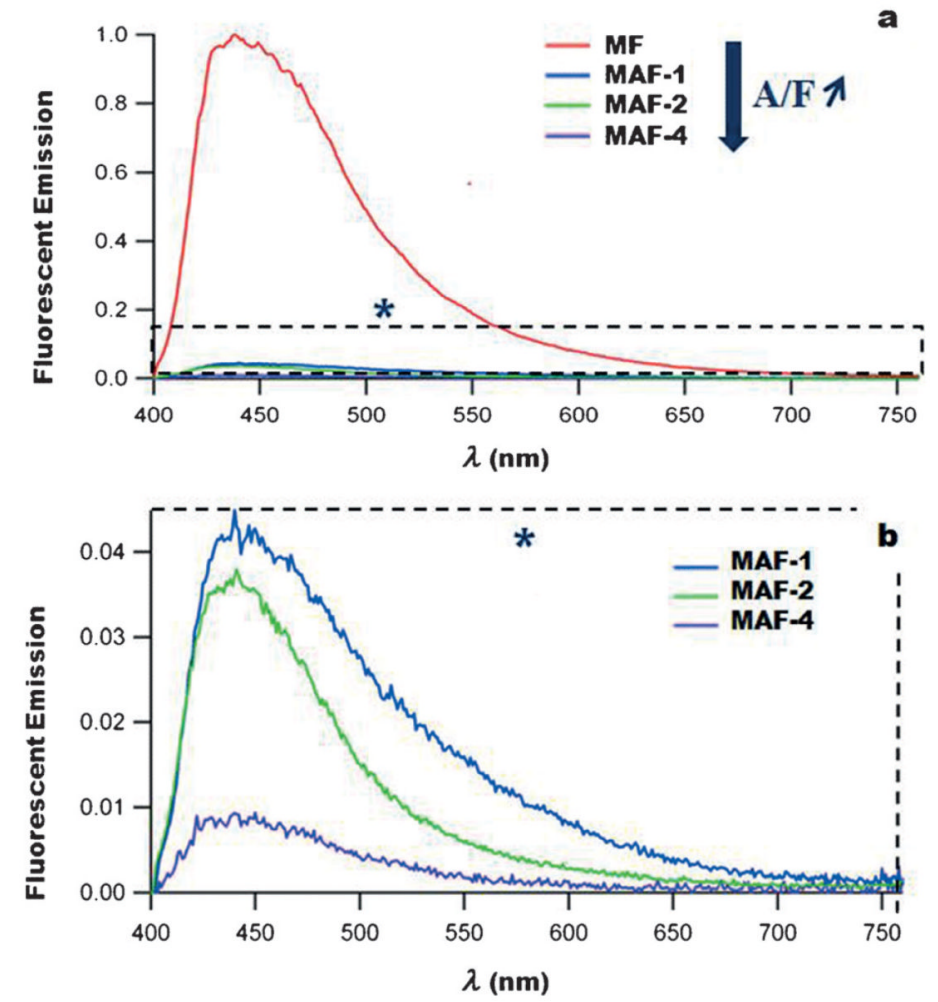

Figure 1.

Fluorescence properties of MF and MAF nanoparticles $\left(\lambda_{\mathrm{ex}}=385 \mathrm{~nm}\right)$. The fluorescence emission of the fluorophore which vanishes when the A/F ratio increases shows the energy transfer. 


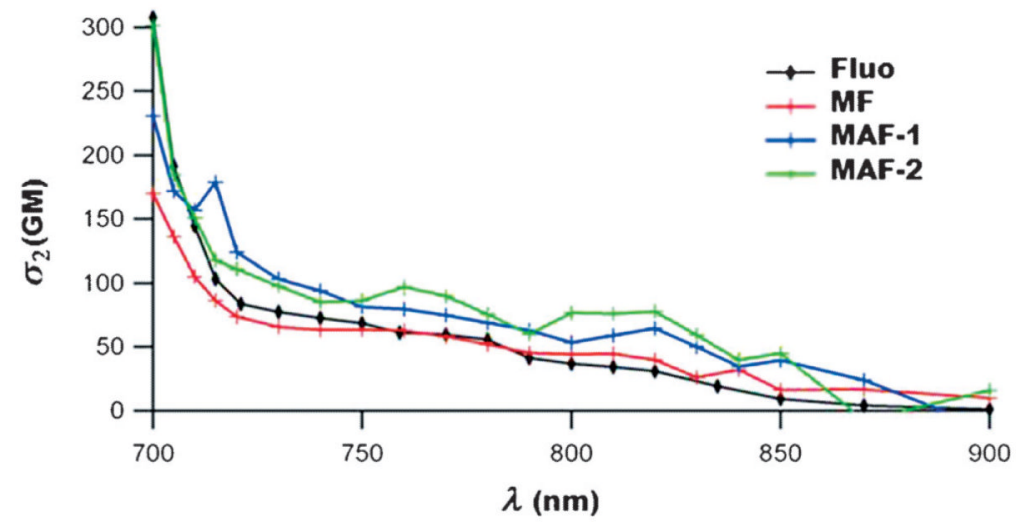

Figure 2.

Two-photon absorption cross-sections of MF and MAF, compared with the fluorophore in ethanol. 


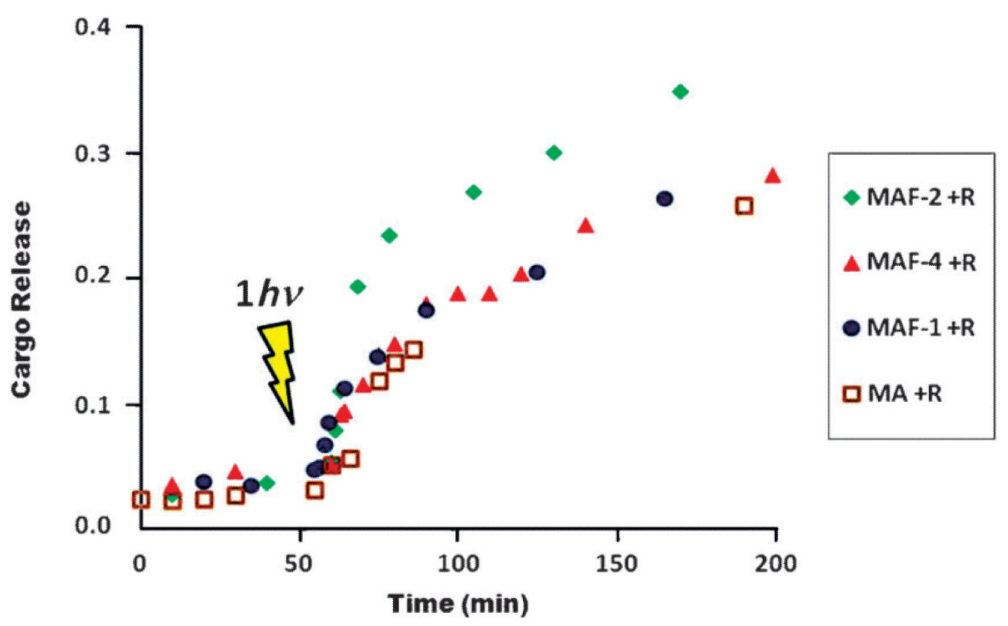

Figure 3.

One-photon-triggered rhodamine $\mathrm{B}$ delivery in water. Comparison between nanoimpellers $\mathrm{MA}+\mathrm{R}, \mathrm{MAF}-1+\mathrm{R}, \mathrm{MAF}-2+\mathrm{R}$, and MAF-4+R. 


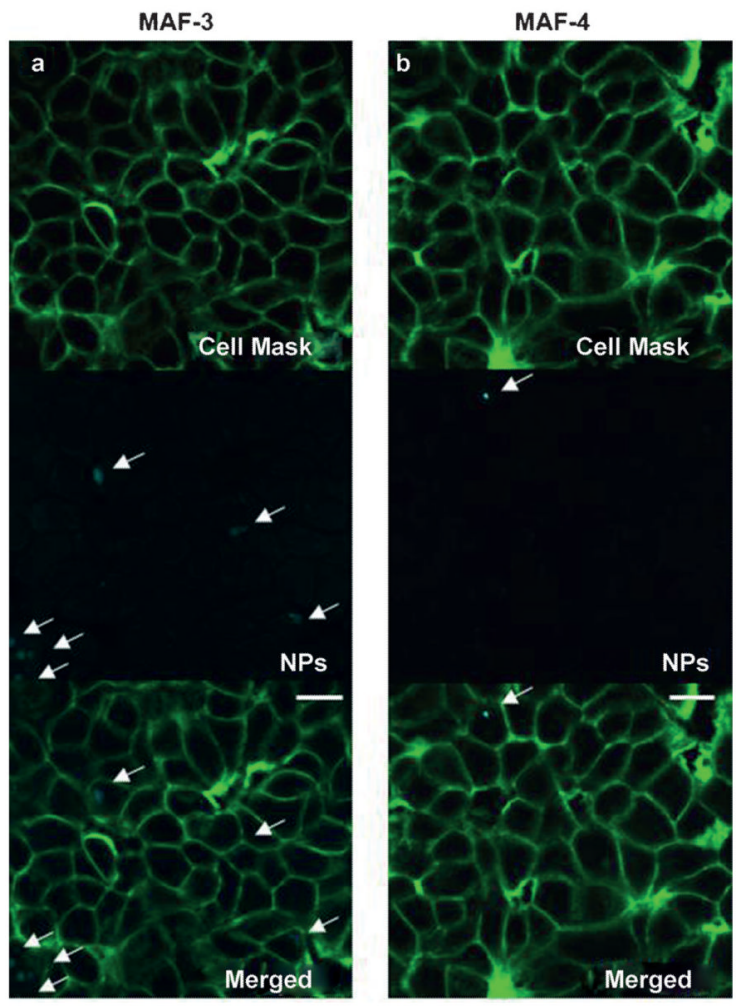

Figure 4.

Two-photon fluorescence imaging of a) MAF-3, and b) MAF-4 confirming the cellular uptake of the nanoimpellers (the scale bars are $10 \mu \mathrm{m}$ ). 

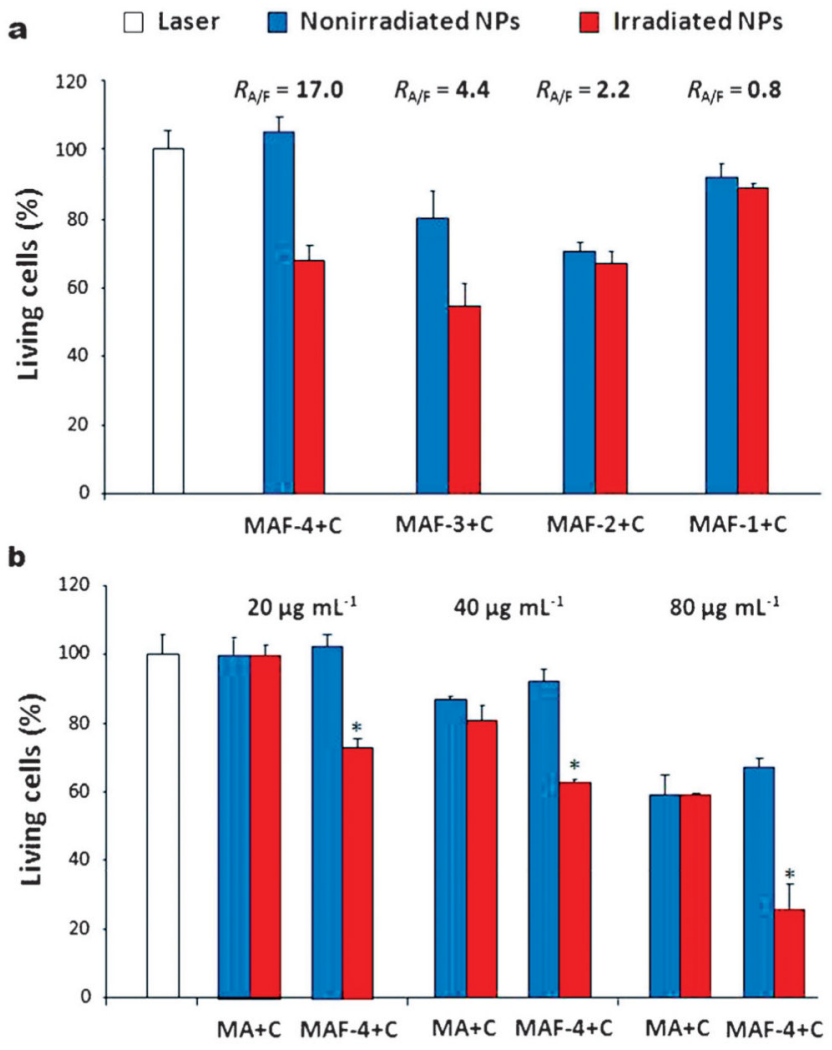

Figure 5.

Two-photon-triggered in vitro delivery of camptothecin, comparison between a) nanoimpellers MAF- $1+\mathrm{C}, 2+\mathrm{C}, 3+\mathrm{C}, 4+\mathrm{C}$, at $20 \mathrm{\mu gmL}^{-1}$ and b) MA and MAF-4 at 20-80 $\mu \mathrm{gmL}^{-1}$. Data are mean values \pm standard deviation from three independent experiments. * Statistically significant versus nonirradiated nanoparticles $(p<0.05$ from Student's $t$ test; $R_{\mathrm{A} / \mathrm{F}}=\mathrm{A} / \mathrm{F}$ ratio). 


\section{Table 1}

Characteristics of MA, MF, and MAF nanocarriers.

\begin{tabular}{lllll}
\hline NPs & A/F Ratio & $\boldsymbol{n}_{\mathbf{0}}$ Azo $[\mathrm{mol}]^{[a]}$ & $\boldsymbol{n}_{\mathbf{0}}$ Fluo $[\mathrm{mol}]^{[a]}$ & $\boldsymbol{S}_{\text {BET }}\left[\mathbf{m}^{2} \mathbf{g}^{-1}\right]^{[a]}$ \\
\hline MA & - & $3.7 \times 10^{-4}$ & 0 & 1144 \\
MF & 0 & 0 & $1.0 \times 10^{-5}$ & 991 \\
MAF-1 & 0.8 & $4.0 \times 10^{-5}$ & $5.0 \times 10^{-5}$ & 1066 \\
MAF-2 & 2.2 & $2.2 \times 10^{-4}$ & $1.0 \times 10^{-4}$ & 851 \\
MAF-3 & 4.4 & $2.2 \times 10^{-4}$ & $5.0 \times 10^{-5}$ & 658 \\
MAF-4 & 17.0 & $1.7 \times 10^{-4}$ & $1.0 \times 10^{-5}$ & 745 \\
\hline
\end{tabular}

${ }^{[a]}$ Azo $=$ azobenzene moieties, Fluo = fluorophore, and $S_{\mathrm{BET}}=$ Brunauer - Emmett-Teller surface. 


\section{Table 2}

Photophysical properties of MA, MF, and MAF nanocarriers ( $\Phi_{\mathrm{F}}=$ fluorescence-emission quantum yield and $\Phi_{\mathrm{ET}}=$ energy-transfer quantum yield).

\begin{tabular}{|c|c|c|c|c|}
\hline NPs & $\begin{array}{l}\lambda_{\text {abs }} / \lambda_{\text {em }} \\
{[\mathrm{nm}]}\end{array}$ & $\Phi_{\mathrm{F}}[a]$ & $\Phi_{\mathrm{ET}}[a]$ & $\sigma_{2}^{\max [b]}[\mathrm{GM}]$ \\
\hline MA & $368 /-$ & 0 & - & - \\
\hline MF & $385 / 441$ & 0.58 & - & 170 \\
\hline MAF-1 & $382 / 441$ & 0.025 & 0.95 & 230 \\
\hline MAF-2 & $378 / 441$ & 0.022 & 0.96 & 300 \\
\hline MAF-4 & $370 / 441$ & 0.005 & 0.99 & - \\
\hline
\end{tabular}

